\title{
MODERN WOUND TREATMENT WITH DEVICES WORKING ACCORDING TO VARIOUS PHYSICAL PRINCIPLES
}

Miklós Szokoly ${ }^{1}$, Petra Aradi ${ }^{2}$

${ }^{1}$ Péterfy Hospital and Trauma Center

${ }^{2}$ Department of Mechatronics, Optics and Engineering Informatics, Budapest University of Technology and Economics

orvig@peterfykh.bu

\begin{abstract}
The prevalence of venous diseases in Europe is $25.2 \%$. According to studies of the University of Bonn this number can be as high as $90 \%$. Optimistic estimates suggest this number to be $27.5 \%$ in Hungary, $21.5 \%$ in Germany. Treatment costs of varicosis and its complications are covered by $2 \%$ of the annual healthcare expenditure in Western countries. Chronic venous insufficiency (CVI, or chronic venous disease, CVD) affects $1.7 \%$ of European population, and can lead to venous ulcers. In Hungary $0.5-1 \%$ of the population suffers from venous ulcers, which is a result of primary or secondary varicosity.

Although an increasing number of modern wound dressings have appeared during the last decade, the treatment of ulcerous wounds in necrotic and exudative phases requires additional methods, either conventional or surgical. Infrared light is used to discover pathologic veins. Beside sclerotherapy and surgical treatment external and internal (so called intraluminal) methods are used. Leg ulcers of venous origin in various phases can be cleaned with ultrasound devices, vacuum therapy or high pressure water. Hyperbaric oxygen treatment, keratinocytes, magnetic treatment, laser wound care and skin transplantation can be used as adjuvant.

Authors present the aforementioned procedures with examples. New devices and methods help to reduce healing time and to avoid amputation in cases that are often considered hopeless.

Technical advancement and modern wound dressings permit successful treatment and healing of wounds that earlier were untreatable, however monetary shortage and the current status of healthcare.
\end{abstract}

Keywords: chronic wound, venous leg ulcer, treatment, wound care technologies.

\section{Introduction}

The prevalence of venous diseases in Europe is $25.2 \%$. According to studies of the University of Bonn this number can be as high as $90 \%$. Optimistic estimates suggest this number to be $27.5 \%$ in Hungary, $21.5 \%$ in Germany. Treatment costs of varicosity and its complications are covered by $2 \%$ of the annual healthcare expenditure in Western countries. Chronic venous insufficiency (CVI, or chronic venous disease, CVD) affects $1.7 \%$ of European population, and can lead to venous ulcers. In Hungary $0.5-1 \%$ of the population suffers from venous ulcers, which is a result of primary or secondary varicosity.

In Hungary the majority is leg ulcers is detected in population around 70 years of age. Femalemale ratio is $3: 1$. It is unfortunate that only $29 \%$ of patients reports for treatment. The situation is 
much direr for diabetic patients. in 2003 the number of diabetes patients was 194 million worldwide, $5.1 \%$ of population. The predicted number of patients for 2025 is 333 million, 6.3\% of population. In people suffering from diabetes wounds form 40 times more often, than in healthy population. Micro- and macroangiopathic complications reduce life expectancy by 6-10 years. $50 \%$ of the total of 5,000 non-traumatic amputations are performed on diabetics. During the first year after amputation $10 \%$ of patients die, in the fifth year mortality is $70 \%$.

Another category is the wounds that appear in connection with various types of peripheral artery occlusive disease.

If treatment of wounds of leg ulcers is started immediately after their formation, healing chances are far better, than treatments started at a later phase. This paper focuses on treatment equipment and methods of previously untreated wounds, with the threat of amputation.

\section{Method}

Ulcers are classified according to Wagner ${ }^{1}$ (Table 1). This primary classification is the basis of selecting treatment method and the type of wound dressing.

\begin{tabular}{|l|l|}
\hline Grade 1 & No ulcer in a high risk foot. \\
\hline Grade 1 & Superficial ulcer involving the full skin thickness, but not underlying tissues. \\
\hline Grade 2 & $\begin{array}{l}\text { Deep ulcer, penetrating down to ligaments and muscle, but no bone } \\
\text { involvement or abscess formation. }\end{array}$ \\
\hline Grade 3 & Deep ulcer with cellulitis or abscess formation, often with osteomyelitis. \\
\hline Grade 4 & Localized gangrene. \\
\hline Grade 5 & Extensive gangrene involving the whole foot. \\
\hline
\end{tabular}

Table 1. Wagner's Foot Ulcer Grading System ${ }^{1}$

General principles concerning chronic wounds are as follows

- wounds are considered septic and treated accordingly

- treatment principle depends of stage

- wounds are kept open

- modern wound treatment is based on bacteriological tests

- alginates, silver-containing ointment dressings, hydrocolloids and hydrogels are used to keep wounds moist

- wound surroundings have to be protected, however iodine, mercurochrome (merbromin) and antiseptic wound powders have to be avoided

- load relief

Phases of chronic wounds are necrotic, exudative, granulation, and ephitelisation. Description and treatment are summarized in Table 2.

Wound debridement devices working along various physical principles are used in exudative phase. Exudative or infected phase wounds are painful and tender, have ample purulent exudates on the wound base, redness, warmth and induration appears in adjacent tissues. Exudative wounds need to be cleaned to the basis, resulting in a bleeding fresh wound. Then as in acute wounds, wound healing can commence. 


\begin{tabular}{|l|l|l|}
\hline \multicolumn{1}{|c|}{ Phase } & \multicolumn{1}{|c|}{ Treatment } & \multicolumn{1}{c|}{ Dressing } \\
\hline necrotic & $\begin{array}{l}\text { necrectomy, debridement } \\
\text { mechanic } \\
\text { surgical } \\
\text { enzymatic } \\
\text { protection of peri-ulcer area }\end{array}$ & $\begin{array}{l}\text { washing with disinfectants } \\
\text { alginate } \\
\text { active carbon compresses } \\
\text { enzymatic dressings } \\
\text { hydrogel } \\
\text { absorbents } \\
\text { daily dressing change }\end{array}$ \\
\hline exudative & $\begin{array}{l}\text { mechanic } \\
\text { surgical } \\
\text { hydrosurgical cleaning } \\
\text { ultrasound assisted cleaning } \\
\text { enzymatic } \\
\text { negative pressure wound therapy } \\
\text { protection of peri-ulcer area }\end{array}$ & $\begin{array}{l}\text { washing with disinfectants } \\
\text { alginate } \\
\text { active carbon compresses } \\
\text { enzymatic dressings } \\
\text { absorbents } \\
\text { silver nanoparticles } \\
\text { daily dressing change }\end{array}$ \\
& $\begin{array}{l}\text { protection of peri-ulcer area } \\
\text { dressing change every 2-3 days }\end{array}$ & $\begin{array}{l}\text { hydrogel } \\
\text { hydrocolloid } \\
\text { impregnated compresses } \\
\text { absorbents }\end{array}$ \\
& & $\begin{array}{l}\text { hydrogel } \\
\text { impregnated compresses }\end{array}$ \\
\hline granulation & dressing change every 3-4 days & \\
& &
\end{tabular}

Table 2. Phases of chronic ulcers

\section{Hydrosurgical wound debridement}

Hydrosurgery means the use of high speed concentrated fluid flow instead of traditional mechanical devices. Necrotic tissue, bacteria and other contamination can be removed with high precision, while creating a smooth wound bedand preserving as much viable tissue as possible.

Smith \& Nephew's Versajet Hydrosurgery System (Figure 1), winner of the Wall Street Journal's 2006 Technology Innovation Award was tested in ulcer patients, details are presented later in Results.

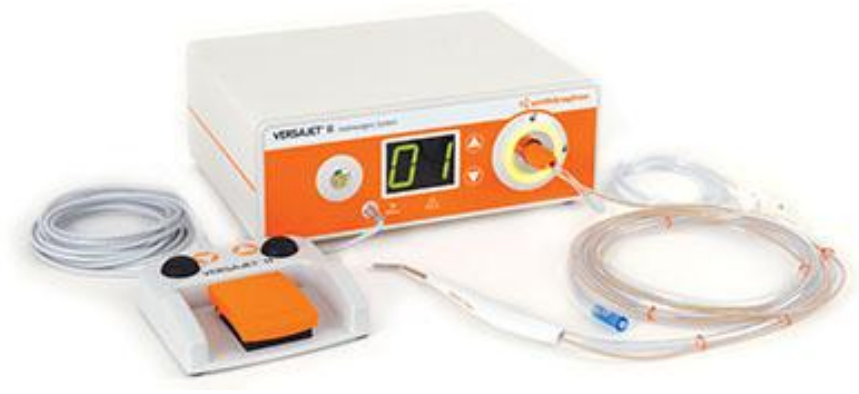

Figure 1. Versajet Hydrosurgery System²

VersaJet's operating principle is the Venturi effect. A high velocity sterile saline stream jets across the operating window, where Venturi effects creates a localized vacuum. This is how removed tissue is simultaneously aspirated from the site. Various settings allow the use of a device for controlling the amount of removed tissue, e.g. at low power levels, it is almost like a vacuumomly cleaner, which removes little or no tissue. With the increase of power tissue ablation increases, too, so tissues with harder consistency get removed. 


\section{Ultrasonic Assisted Wound Treatment (UAW)}

UAW is a non-invasive method using ultrasound energy combined with irrigation solution to clean wounds and promote wound healing.

Söring's ultrasonic assisted wound treatment system ${ }^{3}$ (Figure 3) was tested in ulcer patients, details are presented later in Results.

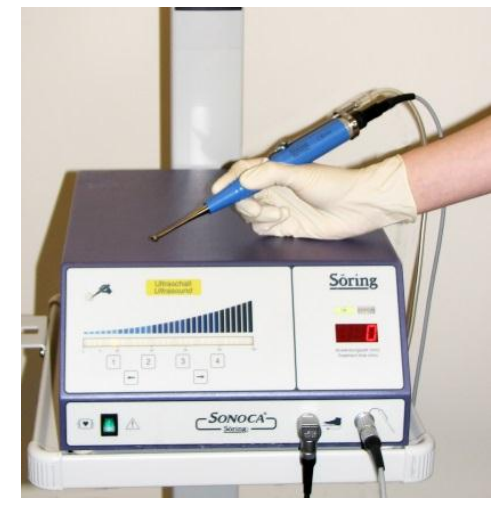

Figure 2. Söring Ultrasonic Assisted Wound Treatment System ${ }^{3}$

The ultrasound generating device is connected to a handpiece that applies $25 \mathrm{kHz}$ low-frequency ultrasound directly to the wound surface with simultaneous saline flow that acts a coupling medium, coolant and wound lavage. The handpiece have three interchangeable tips for different wound surfaces (flat, concave and convex).

Wound debridement is performed via mechanical and cavitational processes with simultaneous intensive flushing of the wound. Necrotic tissue, cell debris, fibrin layer and bacteria are flushed from the wound while healthy granulation tissue is preserved and microvascular circulation is promoted. The method does not destroy granulation tissue, blood vessels, or nerves due to their higher tensile strength.

\section{Other wound treatment methods}

Other promising treatment methods, which hopefully will be widely available in the near future, are hyperbaric oxygen treatment, Bemer magnetotherapy, and various methods of skin replacement. These methods require adequate wound cleaning, and their main purpose is to be adjuvant to the definite therapy.

\section{The importance of modern wound dressings}

Phase-specific wound management of venous leg ulcer needs different types of wound dressings. Quite a number of manufacturers produce such dressings. Alginates, silver-ions, active carbon, hydrocolloids and hydrogels are the most used in wound treatment; however the emphasis has to be placed on wound debridement, preferably with the use of previously mentioned methods, to retain as much of viable tissue as possible.

\section{Results}

The results presented below are direct experience of the first author. One of the patients whose case is presented here had a spontaneous varix rupture (left side of Figure 3), which was followed by skin necrosis. Necrosis progressed rapidly already on the next day (right side of Figure 3). 

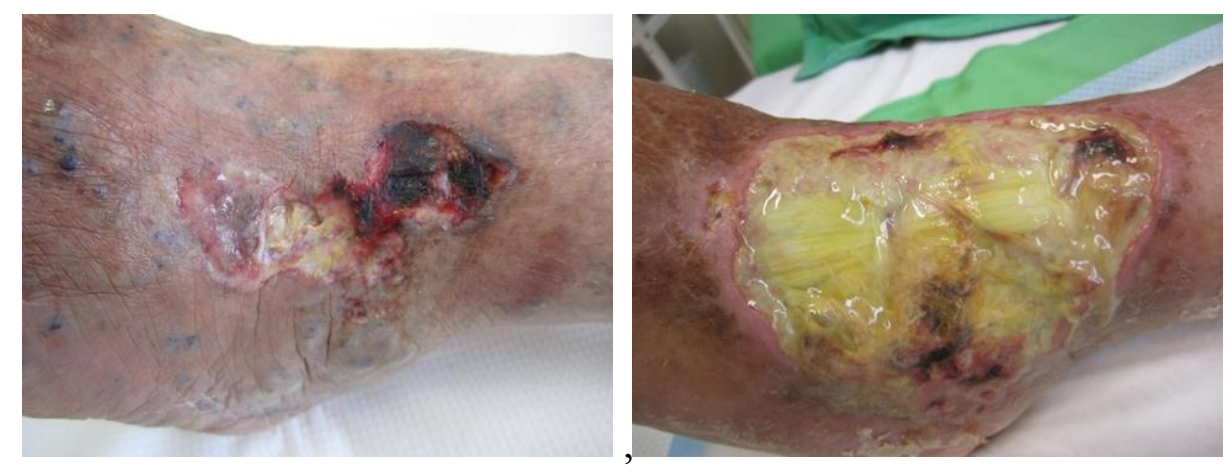

Figure 3. Spontaneous varix rupture and progressive skin necrosis on the next day

Angiography showed a severely narrowed and occluded major blood vessel (Figure 4).

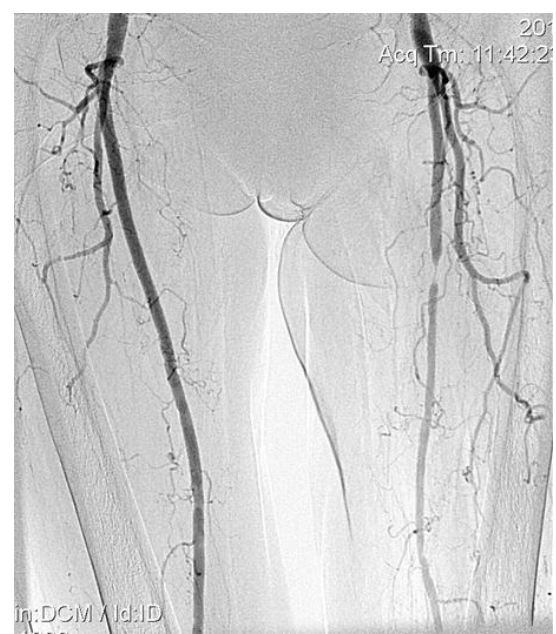

Figure 4. Occluded blood vessel on angiogram

Blood thinning by LMWH treatment had been commenced and the wound was cleaned with Versajet (Figure 5). Wound base was a little bit bloody the next day; however on the third day granulation phase already begun.

Later on Reverdin-grafting was performed (Figure 6). During the whole duration of treatment appropriately chosen modern wound dressings were applied (Figure 6).

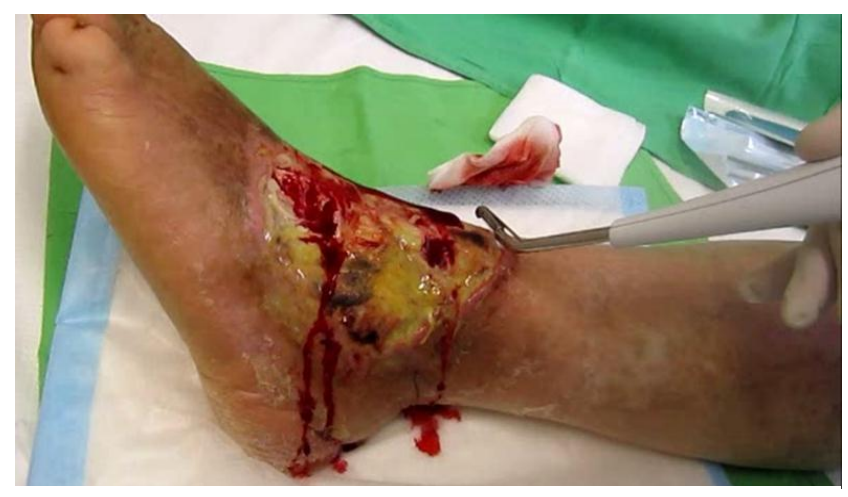

Figure 5. Hydrosurgical wound debridement with Versajet

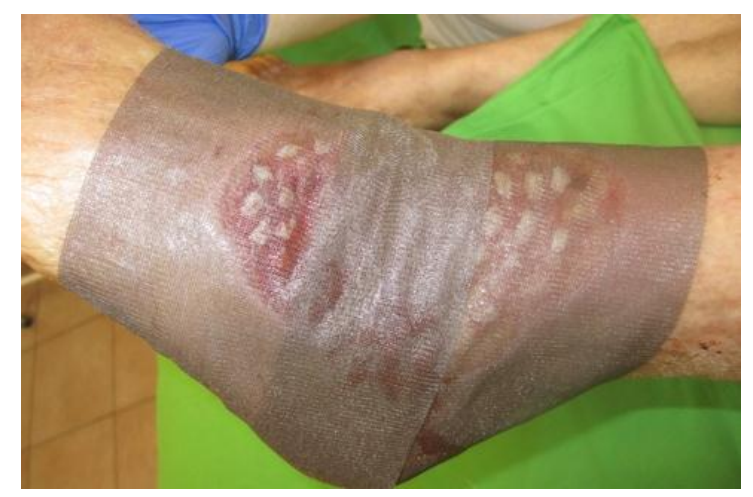

Figure 6. Reverdin-grafting and the use of modern wound dressings 


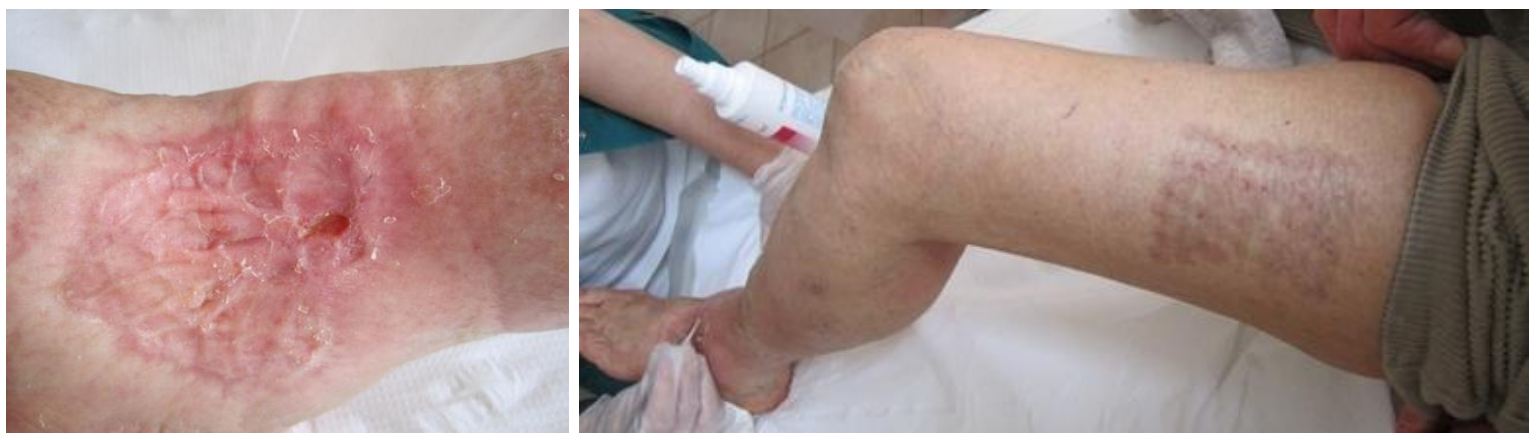

Figure 7. Results of Reverdin-grafting after one month

The second patient, whose case is presented had been given an appointment for urgent amputation, because of the consequences of an infection. Snapshots from the treatment are shown in Figure 8.
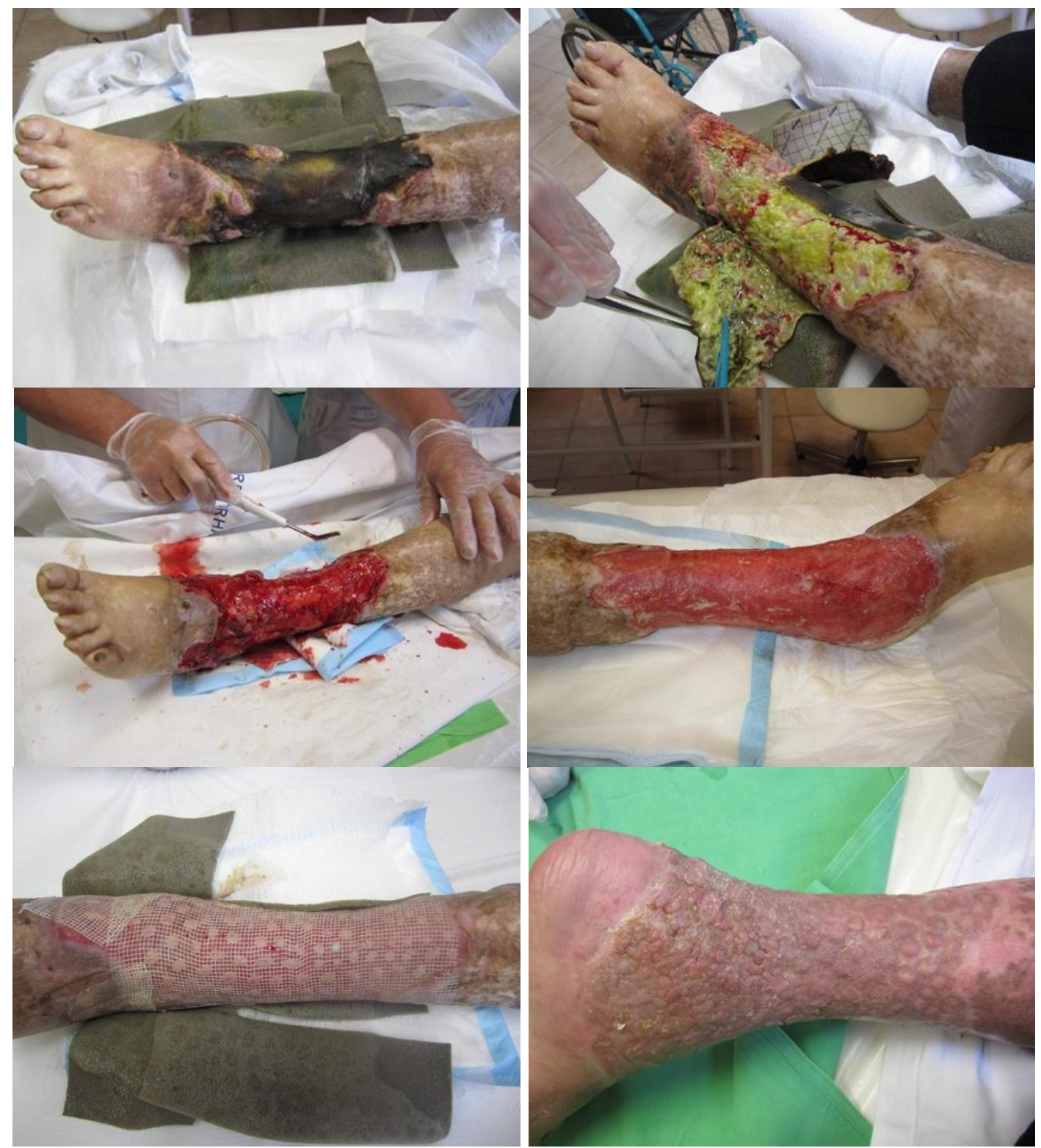

Figure 8. Instead of amputation wound was systematically treated with modern debridement methods and dressings 


\section{Conclusion}

Modern wound cleaning methods have proven their grounds, as one can see in the presented cases. Even in situations considered hopeless and untreatable by conventional wound management, amputation being the only possible outcome; hydrosurgical and ultrasonic wound cleaning together with modern wound dressings helped to save the limb and quality of life.

\section{REFERENCES}

1. Wagner FW, Jr. The diabetic foot. Orthopedics 1987 Jan;10(1):163-72.

2. VERSAJET II Hydrosurgery System. http://www.smith-nephew.com/key-products/advanced-woundmanagement/versajet/].

3. Söring Ultrasonic Assisted Wound Treatment. http://www.soering.com/applications/wound_treatment/].

Authors would like to thank Hungarian vendors of VersaJet wound debridement system and that of Söring's ultrasonic-assisted wound treatment device for providing devices for evaluation. 